\title{
ENTENDER AL SER HUMANO DESDE LO ORGÁNICO. LA PROPUESTA DE JONAS Y PLESSNER ${ }^{1}$
}

\author{
JUAN JESÚS GUTIERRO CARRASCO \\ Universidad Pontificia Comillas
}

\begin{abstract}
RESUMEN: La cuestión de la relación del hombre con la naturaleza ha sido abordada desde múltiples ópticas a lo largo de la historia del pensamiento. Se ofrece en este artículo la propuesta de los pensadores Hans Jonas y Helmuth Plessner quienes sitúan al hombre enraizado en el dinamismo natural, acentuando, con Jonas, su responsabilidad moral con y sobre este.
\end{abstract}

PALABRAS CLAVE: ser humano; animal; planta; Jonas; Plessner; responsabilidad; naturaleza

\section{Understand the Human Being from the organic. The proposal of Jonas and Plessner}

ABSTRACT: The question of man's relationship with nature has been approached from multiple perspectives throughout the history of thought. This article offers the proposal of the thinkers Hans Jonas and Helmuth Plessner who place the man rooted in the natural dynamism and accentuating, with Jonas, his moral responsibility with and on this.

KEY WORDS: human being; animal; plant; Jonas; Plessner; responsibility; nature

\section{INTRODUCCIÓN}

Frente a la visión analítico-estructural se abrió paso, en la segunda mitad del siglo XX, una comprensión holística de la vida. Aquí se sitúan autores como Arnold Gehlen, Helmuth Plessner y Hans Jonas. En este artículo intentaremos hacernos cargo de las propuestas de los dos últimos.

Ambos se enfrentan a la cuestión del ser humano desde una filosofía de lo orgánico, entendiendo al hombre desde el continuo naturaleza-vida-vida humana, pero con la pretensión de subrayar con rotundidad los elementos propios que constituyen la verdadera esencia de lo humano.

El hilo conductor de la filosofía que nos lleva del organismo al ser humano es para Plessner la «posicionalidad», mientras que para Jonas será la «creciente mediatez». En ambas nos encontraremos con una visión del hombre enraizada en el dinamismo natural (superación del dualismo) y acentuaremos, con Jonas, su responsabilidad moral con y sobre la naturaleza.

1 Este artículo se enmarca en el Proyecto de investigación: «La condición humana ante los retos de la Ecología» de la Cátedra Francisco José Ayala de Ciencia, Tecnología y Religión de la Universidad Pontificia Comillas (2016-2019).

Fue presentado como comunicación en el LV Congreso de Filosofía Joven celebrado el 16 de mayo de 2018 en la Universidad de Murcia. 
1. Helmuth Plessner. La posicionalidad. Los grados o etapas de lo orgánico

Helmuth Plessner, considerado uno de los iniciadores de la antropología filosófica, defiende que el hombre es un ser de una pieza donde acontece la unión indisoluble entre interioridad y exterioridad. Para lograr esa unidad, contraria al dualismo cartesiano, Plessner adopta la categoría de "posicionalidad», concepto que se circunscribe a los seres vivos que mantienen relaciones con su entorno. Ahondemos en su propuesta.

En 1928 Plessner publica Los grados de lo orgánico y el hombre 2 , obra en la que, prescindiendo del apoyo directo en la experiencia, ofrece una investigación sintético-a priori de la vida. En ella propone una «teoría apriorística de los caracteres orgánicos esenciales» en el centro de la cual sitúa el principio de posicionalidad.

La posicionalidad es algo más que un lugar natural: ni es el entorno, ni es la forma descrita por el entorno, sino que remite al modo peculiar de comportamiento del ser vivo con respecto a sí mismo y a su entorno ${ }^{3}$.

Plessner describe dos tipos de relaciones del organismo con el entorno ${ }^{4}$ :

«I. El primero se refiere a la corporalidad inorgánica, para la cual el entorno, idéntico a su forma externa, es simplemente el punto donde el cuerpo se detiene. Un pedrusco o una caja están simplemente donde están y se detienen donde se detienen. Es decir, el cuerpo inanimado es hasta donde él mismo alcanza. Donde acaba, acaba también su ser. En este caso tenemos la relación $\mathrm{C} \leftarrow \mathrm{L} \rightarrow \mathrm{M}$ (Cuerpo $\leftarrow$ Límite $\rightarrow$ Medio).

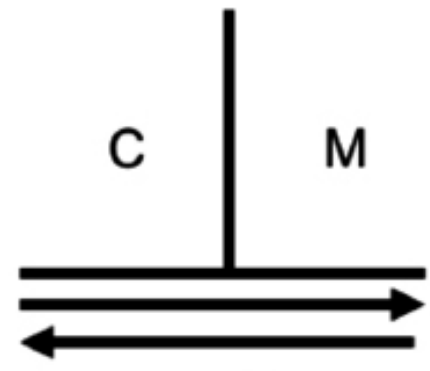

1.

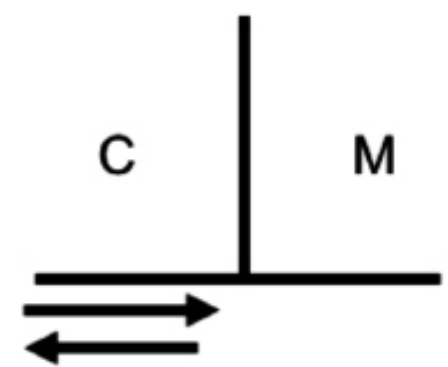

2.

2 Esta obra no se encuentra traducida al castellano. Sí la encontramos en italiano: Plessner, H., I gradi dell' organico e l'uomo. Introduzione all' antropologia filosofica, Bollati Boringhieri editore, Turín 2006.

De Plessner encontramos en castellano las siguientes obras:

- La risa y el llanto, Trotta, Madrid 2007.

- Límites de la comunidad. Crítica al radicalismo social, Ediciones Siruela, Madrid 2012.

- La nación tardía. Sobre la seducción política del espíritu burgués, Biblioteca Nueva, Madrid 2017.

3 González, A., «La posicionalidad excéntrica del hombre» en: Anuario Filosófico, 4 (1971), 158.

4 Diagrama hecho por Plessner y recogido en Plessner, H., I gradi dell' organico e l'uomo. Introduzione all' antropologia filosofica, Bollati Boringhieri editore, Turín 2006, p. 154. 
II. El segundo tipo es el de la corporalidad orgánica, para la cual el entorno es una parte de ella misma, un efectivo entorno perteneciente al cuerpo y que se enfrenta al medio y, desde luego, también al cuerpo del que es entorno. Las cosas vivas, a diferencia de las anteriores, tienen el entorno como parte de sí mismas, como parte de sus cuerpos. La relación del cuerpo con su entorno es una relación de él mismo con él mismo ${ }^{5}$. En este caso tenemos la relación $\mathrm{C} \leftarrow \mathrm{C} \rightarrow \mathrm{M}$.

Nos encontramos aquí con una "duplicidad de aspecto" o "doble aspectividad", pues los seres vivientes diferencian en sí mismos un interior y un exterior; "a través de su relación con el entorno están a un tiempo dirigidos hacia afuera, más allá del cuerpo que es, y, de vuelta, hacia su interior" ${ }^{6}$.

Centrémonos en el caso de la vida, donde el límite pertenece al viviente mismo como tránsito que opera la delimitación del cuerpo viviente y su apertura, haciéndole salir de sí y desbordarse hacia el medio situado frente a él.

El límite del viviente es así, para Plessner ${ }^{7}$, tránsito y permanencia, apertura y contención. Es en el proceso vital donde se consuma el equilibrio entre devenir y permanencia, donde algo permanente desemboca, a través de la transformación del devenir, en algo nuevo y permanente.

Esta progresión de la naturaleza viviente sitúa a los reinos naturales en una sucesión que va del reino vegetal al humano, en función de la mayor o menor independencia del organismo respecto al ambiente y a sí mismo. Para ello Plessner emplea la categoría a priori, antes mencionada, de la posicionalidad, según la cual «todo lo vital es unidad organizada centralmente (alcanzando su grado más alto en la autoposesión del hombre como fruto de la reflexión) y, al mismo tiempo, es apertura activa hacia el entorno» ${ }^{8}$.

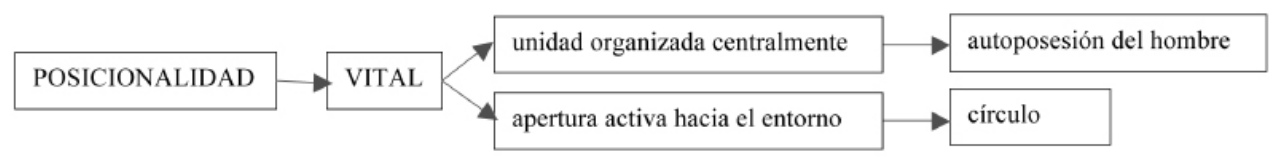

En esa apertura, el viviente erige un «círculo vital» que, dependiendo de su forma (abierta o cerrada) determina su grado de dependencia o de autonomía. De este modo, se produce un flujo recíproco constante entre organismo y entorno, como ocurre en el fenómeno del metabolismo, así como en la capacidad que tiene de adaptación al medio.

5 GreEne, M., «El concepto de posicionalidad. Introducción a la filosofía de Helmuth Plessner» en: Convivium, 22 (1966) 45.

6 Ibid., p. 46.

7 GonzÁlez, A., op. cit., p. 169.

$8 \quad$ Ibíd. 
Ahora bien, esta forma es una categoría a priori, por lo que únicamente es captable mediatamente, por ello es imposible establecer una diferencia empírica entre la forma abierta de la planta y la forma cerrada del animal: «La planta y el animal no pueden distinguirse esencialmente sobre la base de características empíricas. Su diferencia es, en realidad, ideal»?.

Plessner establece así una «diferenciación posicional» apriórica entre los diferentes reinos de la naturaleza, entendiéndola como un verdadero principio constitutivo de la misma naturaleza, de la cual se originan los distintos niveles orgánicos.

\subsection{Las plantas y su forma abierta}

En esta escala posicional se encuentran, en primer lugar, las plantas. El organismo vegetal está marcado por una forma abierta:

«Es abierta aquella forma que inserta el organismo, en cada manifestación vital, inmediatamente en el entorno y lo convierte en una parte no independiente de su círculo vital correspondiente» ${ }^{10}$.

Es imposible, por tanto, distinguir en el mundo vegetal entre mundo interno y externo "porque no hay un centro, un «sí mismo» que confiera conciencia al sujeto» ${ }^{11}$. La planta está integrada en el medio, de lo cual se siguen sus propiedades básicas: son autotróficas, ninguna posee locomoción ni funciones sensoriales. "La individualidad es un atributo de la planta, pero no como algo constitutivo sino como puro momento exterior de su forma ${ }^{12}$, es decir, el árbol, si bien es un individuo visible, no posee un órgano central, no es, señala Duch, un individuum, sino un dividuum: en sentido propio es incapaz de moverse voluntariamente. De ahí que su forma no alcance la plenitud, sino que siempre esté incompleta, un inacabamiento que le es intrínseco ${ }^{13}$.

\subsection{El animal y su forma cerrada.}

En el segundo nivel se sitúa el reino animal, al cual le distingue la categoría a priori de la forma cerrada:

9 Traducción propia de Plessner, H., I Gradi... op. cit., p. 259: «La pianta e l'animale non si possono distinguiré essenzialmente su la base di caratteristiche empiriche. La loro differeza è in realtà ideale. Forma aperta e forma chiusa sono idee secondo le quali i corpi viventi reali si danno como corpi organici; sono idee sotto le quali compare il vivente nel percorrer la via dell'oraganico. Sul piano empírico la línea di dimarcazione tra il regno vegetale e quello animale non si può trovare; qui, accanto alle forme definite, si trovano delle forme di passaggio».

10 Traducción propia de Plessner, H., I Gradi... op. cit., p. 244: «E aperta quella forma che inserisce l'organismo, in ogni sua esternazione vitale, inmediatamente nell'ambiente e lo rende una parte non indipendente del ciclo vitale a lui corrispondente».

11 Duch, L., «Introducción a la edición española» en: Plessner, H., La risa y el llanto, Editorial Trotta, Madrid 2007, p. 17.

12 GonZález, A., op. cit., p. 171.

13 Duch, L., op. cit., p. 17. 
«La forma cerrada es aquella mediante la cual el organismo, con todas sus manifestaciones vitales, se inserta en el entorno de forma mediada, convirtiéndolo en una parte independiente respecto de su círculo vital correspondiente» ${ }^{14}$.

Existe así una oposición entre cuerpo y medio que establece una separación del entorno, enfrentándose a él, aunque sigue expuesto a él. Entre el animal y el medio ambiente se interpone un estrato intermedio: el cuerpo (Körper). De este modo, el viviente ya no entra directa ni inmediatamente en contacto con el medio, como ocurre en el caso de la planta ${ }^{15}$.

Plessner postula la existencia de un punto inespacial en el cuerpo: centro, núcleo, sujeto, un núcleo de relación en el viviente que tiene la capacidad de distanciarse del propio cuerpo (Körper), manteniendo la plena vinculación con el mismo y, de esta manera, el cuerpo (Körper) es constituido en «realidad somática» $(\text { Leib })^{16}$. Esta constitución, es decir, el «tener sujeto» se hace explícita en la vida animal gracias a la mediación de un centro que realiza la actividad sensorio-motora y que, por tanto, permite la acción. Es el sistema nervioso el que representa el centro, actuando como mediador entre el sujeto, su cuerpo como su cuerpo, y el entorno como exterior, como todo lo que no es "él mismo». Es en este nuevo nivel de mediación de la organización animal donde éste alcanza su mismidad. Llega a ser un individuo, aunque no un yo. Tiene un cuerpo y es un individuo, pero no tiene una individualidad ${ }^{17}$.

En el absoluto aquí y ahora en el que se encuentra el cuerpo en su entorno, éste le amenaza y le ofrece oportunidades ante las que el animal actúa, manifiesta su espontaneidad. Tiene, frente a las plantas, una nueva dimensión de libertad. Y como agente se enfrenta al mundo: manifiesta lo que Plessner llama la frontalidad. No sólo ocupa un lugar, sino que se sitúa: es el fundamento de la aparición de la conciencia. El animal es un organismo dotado de conciencia en tanto que tiene la capacidad de distinguirse y enfrentarse a su entorno y de oponerse a él, aunque no sea consciente de que lo hace: «El animal vive en su centro y a él retorna, pero no vive como centro», es decir, no posee capacidad reflexiva, no tiene consciencia de lo que hace porque aún no es un "yo». Aunque sepa conocer y actuar, el animal no tiene consciencia de sus conocimientos y acciones ${ }^{18}$.

14 Traducción propia de Plessner, H., I Gradi... op. cit., p. 251: «La forma chiusa è quella mediante cui l'organismo, con tutte le sue manifestazioni vitali, si inserisce nell' ambiente in modo mediato, rendendolo una parte indipendente del ciclo vitale a lui corrispondente».

15 GonZÁlez, A., op. cit, p. 171.

16 Ibid., pp. 171-172.

17 Green, M., op. cit., pp. 55-56.

18 La investigación, hasta la fecha, ha demostrado la capacidad de los organismos del reino animal de percibir su propia existencia y la del mundo a su alrededor. Cambridge Declaration on Consciousness (2012). 


\subsection{El hombre. Ser excéntrico.}

Si bien los hombres son animales, no sólo viven a partir de su centro (tiene un Körper, como los demás vivientes) y en su centro (Leib, como los animales), sino que también son el centro mismo, viven en cuanto centro. El hombre no puede liberarse de su existencia centrada, animal, pero se pone a sí mismo frente a ella volviéndose excéntrico, una vida fuera del centro que se vuelve reflexiva. Es lo que Plessner denomina posicionalidad excéntrica. El hombre se halla aún ligado a su naturaleza animal y, sin embargo, es independiente de ella, libre frente a ella. Su vida está en todas partes y en ninguna. Es un nuevo hiatus, una nueva ruptura en la naturaleza que produce una nueva unidad:

«La posicionalidad es una situación de tres caras; la cosa viviente es cuerpo, existe en su cuerpo (como vida interior...) y fuera del cuerpo como el punto de vista desde el cual es ambas cosas (cuerpo y vida interior). Un individuo posicionalmente caracterizado por esta estructura triple es lo que llamamos persona. Es el sujeto de sus experiencias, de sus percepciones y acciones, y de sus iniciativas. Conoce y quiere» ${ }^{19}$.

Es la persona quien engloba todas estas posiciones, es sujeto de su vivenciar, de sus percepciones y acciones, de su iniciativa. Esto es la consciencia. No sólo conciencia, sentir la propia interioridad, sino ser responsable de ella, responder de ella en la acción. La persona sabe y quiere. Su existencia es un sí mismo que va constituyendo actuando mediante la praxis y la reflexión. Para alcanzar la reflexividad completa es imprescindible que el hombre tome distancia de sí, es decir, que advierta «una diferenciación respecto al punto ocular de la visión y al punto propulsor de la acción $»^{20}$, aunque se sepa idéntico al sujeto que está en el centro.

Al distanciarse de su propio centro, pero manteniendo la proximidad con el sí mismo, se constituye en un "yo" plenamente reflexivo. La excentricidad le constituye al hombre en yo y como tal le sustrae al espacio y le hace atemporal. Afirma Menegazzi siguiendo a Plessner:

«El hombre se caracteriza por tanto como un yo (Ich), como aquel punto de fuga de su propia interioridad situado "detrás de sí mismo" que, abstrayéndose en cada momento de las acciones que la vida ejecuta a partir de su propio centro, constituye el espectador que contempla el campo interior como un escenario, el polo subjetivo que ya no podrá ser objetivado y colocado en posición de objeto $»^{21}$.

Y continúa diciendo:

19 Citado en Green, M., op. cit., pp. 58-59.

20 Menegazzi, T., «Helmuth Plessner: antropología y bio-filosofía a comienzos del siglo XX» en: Thémata. Revista de Filosofía, no 43 (2010) 299.

21 Menegazzi, T., op. cit., p. 299 citando a Plessner. 
«Su existencia se encuentra más acá y más allá del abismo, vinculada al cuerpo, vinculada a la psique, pero a la vez puesta en ninguna parte, sin lugar y sin nada que la vincule al espacio y al tiempo, y así es hombre» ${ }^{22}$

El hombre desborda el círculo cerrado en que el animal vive y encuentra protección. Es nuestra posicionalidad extrínseca la que da a nuestra existencia la ambigüedad de necesidad y libertad, de contingencia bruta y significación ${ }^{23}$. Se ve desprovisto de seguridad haciendo, en ocasiones, de esta indigencia su auténtica morada y refugio. El hombre, «no tiene paz, no tiene patria, no tiene un lugar, no tiene certeza absoluta [...] Vive en una incertidumbre cotidiana que reclama insistentemente la atribución de un sentido ${ }^{24}$.

Podemos decir con Plessner ${ }^{25}$ que el hombre, expuesto a desafíos e interrogantes externos cuya respuesta y comportamiento ha de seleccionar, asume lo que es o puede llegar a ser bajo su propia responsabilidad. El hombre no se agota en su vitalidad biológica, sino que destaca por su potencialidad espiritual, la capacidad para planear, realizar, gozar, padecer, ser creadores de arte y derecho, ser, en definitiva, un ser cultural.

Las características de esa peculiar existencia las recoge Plessner en la formulación de tres leyes antropológicas, las cuales son «interpretaciones de las expresividades humanas a la luz de la tesis de la excentridad del ser humano»:

- Ley de la artificialidad natural.

- Ley de la inmediatez mediata.

- Ley del lugar utópico.

El hombre, en esa fractura existencial entre ser cuerpo y tener cuerpo, debe hacerse para ser. "Eternamente desarraigado», como le caracterizaría Plessner $^{26}$, se procura la estabilidad a través de los medios artificiales: la artificialidad es su naturaleza. Es lo que Menegazzi denomina como «filosofía de la compensación», cuyo origen en Plessner no se debe ni a una caracterización orgánica carente ni a un espíritu deseante, sino que estriba «en su artificialidad natural, en la forma en que la vida humana, en virtud de la complicacióncomplicidad alcanzado por su excentricidad, se relaciona consigo misma». La cultura no es una compensación a cierta inferioridad biológica, sino que responde a la necesidad pre-psicológica y extra-empírica, una "consecuencia del grado de complicación que alcanza el repliegue sobre sí mismo del bíos humano» ${ }^{27}$.

Señalar, por último, con Menegazzi, que el hombre asume la responsabilidad de sí frente a la historia. Así, «toda acción y decisión humana implica unas

\footnotetext{
$22 \quad$ Ibid. p. 300.

23 GreEN, M., op. cit., p. 59.

24 RasinI, V., «La natura organica e l'uomo nel pensiero di Plessner» en: Plesssner, H., op. cit., p. XXIII.

25 Duch, L., op. cit., p. 20.

26 Citado en Menegazzi, T., op. cit., p. 302.

$27 \quad$ Ibid. p. 303.
} 
consecuencias ineludibles en la existencia misma del hombre, el cual nunca actúa y decide únicamente para sí mismo ${ }^{28}$, siendo por ello una decisión arriesgada.

En el crepúsculo de dioses que vive la sociedad del siglo XX y que, podemos extrapolar al XXI, «la base biológica de la existencia humana no ofrece vinculación alguna a la responsabilidad y seriedad intrínsecas a cualquier pretensión de afirmar una humanitas». Por ello Plessner emprende esta tarea de fundar una antropología política que reconozca una visión histórica del mundo y que responsabilice al hombre frente a sí mismo ${ }^{29}$.

Podemos concluir, por tanto, que «la condición humana está empapada de lucha para afirmarse en cada momento en una dirección y en un sentido determinado y para hacerse cargo de un mundo o, mejor dicho, para cumplir de manera pública (frente al tribunal de la historia) ese papel del "sujeto histórico de imputación de un mundo" que su misma naturaleza le otorga» ${ }^{30}$.

\section{Hans Jonas. La mediatez. De las plantas al hombre en GRado CReciente.}

Hablar de Hans Jonas sería, para muchos, hablar de su conocida, y ya manida, ética de la responsabilidad. Sin embargo, él mismo destaca en su biografía su dedicación a la filosofía de la biología y el intento de abordar la cuestión de la vida más allá de reduccionismos materialistas e idealistas.

A ello consagró la que él mismo consideró su obra principal: El principio $v i d a^{31}$. Escrita en 1963, su pretensión última era ofrecer categorías básicas para una nueva ontología. Así dice Jonas en sus Memorias ${ }^{32}$ :

«Mi tesis era que la esencia de la realidad se expresa del modo más acabado en la existencia física del organismo, no en el átomo, no en la molécula, no en el cristal, tampoco en los planetas ni en los astros, etc., sino en el organismo vivo, que es sin duda cuerpo, pero que esconde en su seno algo que va más allá del mero ser mudo de la materia. Sólo si partimos de este punto es posible formular una teoría del ser» ${ }^{33}$.

Y desde esta propuesta aparece el epílogo que anuncia el deber de la filosofía de lo orgánico de conducir a una ética, en cuyo trabajo centrará Jonas el resto de su vida.

\subsection{La forma viva indigente en contacto con el exterior}

Si veíamos anteriormente que para Plessner es la posicionalidad excéntrica del hombre la que determina su indigencia, Jonas sostiene que es la vida

28 Ibid., p. 291.

$29 \quad$ Ibid. p. 293.

$30 \quad$ Ibid. p. 296.

31 Jonas, H., El principio vida: hacia una biología filosófica, Trotta, Madrid 1999 [En adelante se citará con las siglas PV].

32 Jonas, H., Memorias, Losada, Barcelona 2005.

33 Jonas, H., Memorias, op. cit., p. 341. 
misma, desde sus más bajas manifestaciones, la que, al emanciparse la forma de la materia, se vuelve indigente, expuesta. La forma vital es, pues, libre de la materia, pero también dependiente de ella. La independencia de la naturaleza «tiene que pagar el precio completo de la dependencia existencial respecto de la naturaleza $»^{34}$ frente a la estabilidad de la materia muerta.

Para Hans Jonas, la oposición del sí mismo de la vida al mundo exterior, a lo ajeno, es, en virtud de la trascendencia, recepción de lo exterior en lo interior, es capacidad de entrar en contacto con la multiplicidad de lo otro.

La existencia precaria se encuentra, por tanto, en contacto con el mundo. Su identidad es «un producto funcional entre dos instantes y no un estado permanente» y, por tanto, «es de duración precaria y revocable» ${ }^{35}$ ante la inevitable extinción.

En función de sus posibilidades de apertura al mundo, es decir, en la medida en que los seres vivos disfrutan de un horizonte espacial, y debido también a que poseen una subjetividad orgánica dotada de intencionalidad para permanecer en la existencia, los organismos van adquiriendo individuación progresivamente. Así comienza la expansión espacio-temporal que, partiendo de la sensibilidad de los seres unicelulares, culminará en los fenómenos propios de los seres humanos.

Desde esta convicción, para algunos fenomenología, para otros ontología ${ }^{36}$, parte el análisis jonasiano sobre las peculiaridades de la vida vegetal y de la vida animal. En él iremos ascendiendo hasta culminar en el hombre en un procesual aumento de mediatez.

\subsection{Las plantas}

Al igual que en Plessner, Jonas destaca de la planta su unión al entorno, pues del suelo extrae los alimentos, de unas reservas siempre disponibles frente a la escisión entorno-sí mismo del animal, el cual no tiene garantizada la presencia de cuerpos orgánicos. Mientras que la planta absorbe osmóticamente las sustancias alimenticias solubles, el animal ingiere alimentos sólidos exigiéndose, así, un auxiliar «mecánico» antes de proceder a la apropiación metabólica.

De este modo, como bien apunta Jonas, «la planta muestra más bien superioridad que carencias». La planta está eximida de moverse, pues está en continuo contacto con la alimentación, su relación con el entorno es automática, su constante contigüidad con el entorno le permite estar ininterrumpidamente en un intercambio químico.

$34 \quad$ PV, p. 150.

35 PV, p. 151.

36 Traducción propia de: DuARTe, M.B., «Aberturas para o mundo: da sensibilidade vegetativa ao fenômeno mental humano no pensamiento de Hans Jonas» en: Pensando Revista de Filosofia, Vol. 7, n 14 (2016) 91. 
La planta se encuentra así en una situación de independencia que, sin embargo, no puede proponerse, como veremos, como valor vital máximo. De hecho, Jonas, en una de sus definiciones de vida la entiende como sigue:

«La vida es precisamente aquel modo de existencia material en el cual el ser se ha expuesto a la dependencia para adquirir a cambio de ella una libertad que le está vedada a la independencia propia de la materia inmutable» ${ }^{37}$.

Ser independiente metabólicamente puede, sin embargo, bloquear a la planta caminos evolutivos que en el animal serán tomados por la libertad a costa de su dependencia. El intercambio continuo y automático con el entorno contiguo le evita la apertura de cualquier tipo de hiato «debido al cual las necesidades se hiciesen perceptibles como tales y hubiese que emprender una acción bajo el acicate del apetito» ${ }^{38}$. Esto llegará con el animal.

\subsection{Los animales}

En los animales la movilidad, la distancia entre el sujeto y el objeto, entre el instinto y su satisfacción supondrá un paso más en la evolución. Esta distancia, que implica la necesidad de plantearse objetivos remotos, marcará las tres características principales de los animales: el movimiento, la percepción y el sentimiento.

Como bien apunta Jonas, para detectar ese objetivo remoto es necesaria la percepción a distancia; para alcanzarlo el desarrollo de la capacidad de movimiento; para vivenciar lo percibido en la distancia sin que se difumine de modo que el movimiento se mantenga en marcha hasta alcanzarlo, se requiere el deseo: «una satisfacción todavía no asible es la condición esencial del deseo, y a su vez es el deseo quien hace posible la satisfacción aplazada ${ }^{39}$.

Por tanto, en palabras de Jonas:

«La percepción presenta al objeto como "no aquí, pero sí allí”; el deseo presenta al objetivo como «todavía no, pero esperable»: la facultad de moverse, guiada por la percepción e impulsada por el deseo, transforma el allí en aquí y el todavía no en ahora. Sin la tensión de la distancia y el aplazamiento forzado por esta no habría ocasión alguna para el deseo o la emoción ${ }^{40}$.

He aquí donde reside el gran secreto de la vida animal, en el hiato entre interés inmediato y satisfacción mediada. En esa mediatez propia del distanciamiento animal, que abre posibilidades frente a la inmediatez, se manifiestan la sensibilidad, el sentimiento y el movimiento. La distancia implica, por tanto, la escisión en la vida animal misma entre sujeto y objeto.

En esa relación con el mundo entra en juego la libertad animal, pues éste tiene que adaptar sus acciones y estas responden, por tanto, a intereses: «las actividades animales están dotadas de valores y de fines en sí mismos».

\footnotetext{
$37 \quad$ PV, p.156.

38 Ibíd.

39 PV, p. 154.

40 Ibíd.
} 
Entre el animal y su relación primaria con el entorno se interpone la percepción, consiguiendo esa mediatez ya citada. Es la vista ${ }^{41}$ el sentido que separa el organismo y el mundo y lo reunifica en una relación secundaria. En la apertura de esa distancia el sentimiento puede elegir y se desarrollan movimientos de largo recorrido. Pero la vista va aún más lejos y puede dar lugar a una facultad espiritual superior.

\subsection{El hombre}

En el hombre se amplía la mediatez y se aumenta la distancia con el mundo gracias, precisamente, a su capacidad de «elaborar imágenes» ${ }^{42}$. Esa nueva mediatez se consigue con la ampliación ideativa de la percepción $n^{43}$, es decir, al introducir el eidos abstraído y manipulable espiritualmente entre la percepción y el objeto actual:

«El hombre deja de ver directamente las cosas: las ve a través de las rejas de las representaciones obtenidas de su trato con las cosas en ocasiones anteriores, convocadas ahora por el contenido perceptivo actual para dejarse empapar de su carga simbólica y a su vez añadirles algo » ${ }^{44}$.

Es la facultad representacional la que permite al sujeto disponer de las imágenes abstraídas sin tener que estar la cosa misma presente, proporcionando

41 Para Jonas el sentido de la vista es el más completo, caracterizada por:

- la simultaneidad

- la neutralización dinámica

- la distancia que abre a la infinitud

«La simultaneidad de la presentación nos proporciona la noción de presencia duradera, el contraste entre el cambio y lo inmutable, entre el tiempo y la eternidad. La neutralización dinámica nos proporciona la forma como distinta a la materia, la esencia como distinta de la existencia y la diferencia entre teoría y praxis. La distancia, finalmente, nos proporciona la noción de infinitud. El espíritu así se marchó en la dirección que le indicaba la vista» (PV p. 210).

42 Conviene aclarar que Jonas entiende por imágenes una «producción intencional de la semejanza con la apariencia visual de una cosa sobre el medio estático de la superficie de otra cosa» (Jonas, H., Pensar sobre Dios y otros ensayos, Herder, Barcelona 2012, p. 49).

Jonas sostendrá que en la capacidad de elaborar imágenes se encuentra la diferencia específica entre el hombre y el reino animal, incluso en las representaciones más primitivas y toscas. Solo los hombres pasan de las sensaciones a la imagen propiamente, pues sólo ellos perciben la imagen como tal y pueden juzgar lo verdadero o lo falso de las mismas. Es decir, cuando la sensación no nos informa claramente de alguna cosa se suscita la imaginación y con ella se forman las imágenes.

Conviene también apuntar aquí que la facultad de imágenes, la imaginatio o phantasia, es la que permite utilizar los datos sensibles proporcionados por el oído o el tacto. Aún más, "solo una criatura que posea la capacidad visual característica del hombre puede"ver" tocando. [...] Los ciegos pueden "ver" mediante sus manos, no porque carezcan de ojos, sino porque son ser dotados con la facultad general de la visión (...)» (PV p. 128).

$43 \quad$ PV, p. 248.

$44 \quad$ Ibíd., p. 249. 
en sí mismas el material para una experiencia simbólica que se da en la distancia, gracias a la cual, dice Jonas, el sujeto recibe el mundo en sus manos, sin que éste le imponga su presencia ${ }^{45}$.

Son la imagen y la abstracción las que nos llevarán aún a un mayor grado de mediatez, pues nos permitirán que la objetivación se vuelva hacia el sujeto mismo. Aquí nace la reflexión, «en la que el sujeto de toda objetivación comparece ante sí mismo como tal y pasa a ser a su vez objeto de un nuevo tipo de relación consigo mismo cada vez más mediata ${ }^{46}$.

Con la autobjetivación, ejercicio también de la facultad eidética, emerge el hombre, «emerge cuando quien pintó el toro e incluso a su cazador dirige sus miradas a la imagen, imposible de pintar, de su propia conducta y de sus estados anímicos». Dirige una mirada que se asombra, indaga y compara. El hombre, dice Jonas, «configura, experimenta y enjuicia su propio ser interno y su propio hacer externo con arreglo a una imagen de qué debe ser y cómo debe conducirse él mismo» ${ }^{47}$. Es decir, vive la idea de hombre, tiene que vivir con una imagen de hombre impuesta en tanto que ha sido creado a imagen de Dios.

«La imagen del hombre nunca le abandona, por mucho que en ocasiones anhele volver a la dicha de la animalidad. Haber sido creado a imagen de Dios quiere decir tener que vivir con una imagen del hombre» ${ }^{48}$.

Es en la comunicación lingüística social donde el hombre aprende a ver cosas y a hablar sobre ellas a la vez que aprende a decir «yo», descubriendo así su propia identidad, si bien, en su solitaria singularidad.

Para Jonas la escisión sujeto-objeto alcanza su grado más alto en la reflexión sobre sí mismo, cuando se abre la distancia de «ser objeto para sí mismo», es decir, cuando el hombre se tiene a sí mismo. Para conseguir este logro hay que pagar un precio: el sufrimiento: "solo el hombre puede ser feliz e infeliz en virtud de la evaluación de su ser con arreglo a criterios que van más allá de la situación inmediata». El hombre que reflexiona sobre sí mismo, que se mira desde la distancia, vive preocupado por lo que es y lo que desea ser (deseo que se encarna en su imagen), por cómo vive, por lo que hace de sí mismo, por ello sólo el hombre vive abierto a la desesperación que puede llegar a la mayor objetivación de sí: el suicidio, un singular privilegio del hombre.

En esta confrontación consigo mismo el hombre se convierte en una pregunta para sí: Quaestio mihi factus sum. Para encontrar respuestas al ser, para que el hombre se encuentre con el ser, «la historia releva a la evolución y la biología da paso a la filosofía del hombre ${ }^{49}$. La historia es el lugar propio donde

45 El hombre no se mueve entre cosas, sino entre cosas que, simbolizadas por la imagen, adquieren un determinado sentido. Es la función de la imagen simbólica: atribución de sentido a las cosas desde la intimidad deseante.

$46 \quad$ PV, p. 249.

47 Ibíd., p. 250

48 Ibid.

49 PV, p. 251. 
se da la naturaleza de ese encuentro: la libertad del hombre, cuya naturaleza es transhistórica. Ahora bien, para Jonas «la condición de posibilidad de la historia que reside en el hombre no es a su vez histórica sino ontológica ${ }^{50}$.

\subsection{De la reflexión a la acción. El hombre: animal responsable.}

Jonas señala tres características transansimales en el hombre: la herramienta, la imagen y la tumba. En lo referido anteriormente solo hicimos mención de la segunda, a aquello idiosincrásico de su naturaleza: el homo pictor, el hombre simbólico del que hablaba Cassirer ${ }^{51}$, del mundo simbólico, estético, de donde Jonas da el salto al homo sapiens, el ser humano que reflexiona.

Sin embargo, al otro lado de la orilla se encuentra el homo faber, cuyo poder se ha impuesto durante siglos debido a la concepción dominadora de una naturaleza utilitaria. El ser humano se ha valido de la técnica para dominar la naturaleza hasta el punto de convertirlo en un hábito vital, haciendo de ésta una «cloaca de los seres humanos». Así lo afirmó Hans Jonas en el año 1987 al recibir el Premio de la paz otorgado por el mundo editorial alemán. En su discurso, titulado «Técnica, libertad y deber» Jonas explicaba cómo la técnica tiene su origen en la libertad humana: «Actos de esta libertad nos han conducido a la situación actual. Actos de esta misma libertad [...] decidirán acerca del futuro global que, por vez primera, está en sus manos ${ }^{52}$.

La libertad la encontramos en la filosofía de Jonas en la propia biología, en el cuerpo, en el «asombroso cerebro» que ordena el resto de las facultades. El poder de decisión viene ya dado en lo explicado anteriormente, en la imaginación, y es que el ser humano "puede transformar a voluntad las imágenes de las cosas que recordamos y debemos a la vista, proyectar de nuevas, representarse todo lo posible» ${ }^{53}$. Será la voz la que dé forma al lenguaje, el cual es el medio físico de la libertad.

Por ello, el hombre es un ser biológicamente libre por naturaleza y producto de ello extiende su mundo artificial por el mundo natural y «el resto de la naturaleza debe soportarlo» ${ }^{54}$.

El problema ha llegado cuando el hombre ha quebrado el equilibrio simbiótico de la naturaleza. Esto se ha producido no solo, que también, debido al crecimiento rapidísimo de la población, sino por el gran avance del poder tecnológico a causa de la alianza técnica-ciencias naturales.

El hombre se ha vuelto así un ser superior cuyas injerencias e intervenciones resultan amenazadoras sobre la totalidad de la naturaleza terrestre presente y

\footnotetext{
$50 \quad$ PV, p. 252.

51 CASSIRER, E., Antropología filosófica. Introducción a una filosofía de la cultura, FCE, México 1975

52 Jonas, H., Más cerca del perverso fin y otros diálogos y ensayos, Los libros de la catarata, Madrid 2001, p. 124

53 Ibid.

$54 \quad$ Ibíd. p. 125.
} 
también futura, llegando a un punto donde «la victoria desmedida pone en peligro al propio vencedor» ${ }^{55}$.

Este aumento de poder, que proviene del incremento del conocimiento, nos ha de llevar también a caer en la cuenta de las repercusiones globales que implica. De hecho, afirma Jonas, «la libertad debe conocer: merced a ella está en juego el todo, y únicamente ella es responsable de ello» ${ }^{56}$.

Esta visión de la naturaleza como una mina a explotar en pro del beneficio propio proviene de la tradición dualista que nace con el platonismo, al cual siguió después la tradición judeo-cristiana y fue acentuado por la distinción cartesiana entre res cogitans y res extensa.

Sin embargo, podemos hoy afirmar, de la mano de la biología molecular, la paleontología, la copertenencia hombre-naturaleza ${ }^{57}$. Únicamente el hecho de que para Jonas el hombre se sitúe en lo alto de la misma le hace responsable de ella en un mundo desprovisto de valores, desencantado, desmitologizado o secularizado.

Como asegura Gómez-Heras ${ }^{58}$ :

«La naturaleza se despliega en evolución azarosa e indeterminada, siempre abierta al azar y a lo imprevisible, mientras el hombre transforma la mera evolución en historia mediante el uso de su libertad. El poder que el hombre consigue, le crea vínculos nuevos con la naturaleza, generando la cultura ecológica que se despliega en ética y estética. La relación hombre-naturaleza se expande, en ese caso, como empatía, responsabilidad y compromiso y no como explotación».

Esa copertenencia se da también en axiología, pudiendo así afirmarse la posesión por parte de la naturaleza de valores intrínsecos. En palabras de Gómez-Heras:

«La misma naturaleza los posee en sí misma y es responsabilidad humana el esforzarse por descubrir los que la naturaleza atesora, admirarlos por su belleza, respetarlos por su calidad $\aleph^{59}$.

Los valores compartidos entre el hombre y la naturaleza aportan los fundamentos del mundo moral, pues concretizan esa copertenencia en el terreno social. De ahí renace la vieja idea de la lex naturae que reconoce en la naturaleza valores que actúan como normas del comportamiento humano e incluso los canoniza en leyes y programas de acción política.

Lo singular del hombre es, para Gómez-Heras, su mundo moral que tiene como base rasgos específicos de su naturaleza: la razón, la libertad o el lenguaje,

${ }_{55} \quad$ Ibid. p. 126.

$56 \quad$ Ibíd. p. 127.

57 Tanto la certeza científica como las convicciones y decisiones que afectan al ser de las cosas y al sentido de la vida avalan esta copertenencia, adquiriendo, por tanto, el problema ecológico dimensiones morales y existenciales.

58 Gómez-Heras, J. $\mathbf{M}^{\mathrm{a}}$., «Reflexión sobre la relación entre el hombre y la naturaleza» en I Congreso español de ecoética, recogido en las actas, p. 9

59 Ibid., p. 12. 
a lo que Jonas añadía el sentimiento y el deseo, situándolo en una posición de deber y responsabilidad ética hacia la naturaleza.

La ciencia y la metafísica proporcionan para él «las categorías básicas del mundo moral: responsabilidad, reconocimiento y justicia, para que los enunciados teóricos adquieran la eficacia de decisiones prácticas sobre valores morales compartidos por la naturaleza y el hombre ${ }^{60}$.

De manera sucinta la propuesta jonasiana defiende la responsabilidad del hombre que debe llevarnos a una represión de nuestro poder, es decir, «reducir nuestro placer en aras de una humanidad futura que nuestros ojos ya no podrán ver» ${ }^{61}$. Esta responsabilidad no es sólo una idea sino también un sentimiento implantado ${ }^{62}$, por ejemplo, en la relación padre-hijo. De ahí nace el puente entre la ética del prójimo y la ética del lejano, aquel ser imaginario «que todavía no tiene voz para dirigirse a nosotros, pero del que sabemos que ha caído en la arbitrariedad de nuestro poder ${ }^{63}$. La ética, que tienen en cuenta la vida como un valor en sí, como un bien, alcanza una dimensión casi cósmica que va más allá de todo lo interpersonal.

La respuesta a este deber responsable solo puede venir a través del poder colectivo: el poder político. Sin embargo, las democracias occidentales, orientadas a un cortoplacismo, son para Jonas incapaces de aportar soluciones eficaces que puedan al menos remediar las consecuencias más feroces. Por ello, él propone algunas alternativas. Entre ellas la creación de conciencia a través de la educación, la inclusión en el derecho púbico de la protección medioambiental, cambios en los hábitos de consumo teniendo en cuenta las posibles consecuencias y buscando, por ello, el equilibrio en una economía de mercado basada en el liberalismo y que conllevaría restricción de libertad. Y, por último, los shocks producidos por catástrofes reales que infundan terror y nos hagan caer en la cuenta de las consecuencias presentes y futuras de nuestro desenfreno tecnológico.

Es, por último, la razón humana, garante del progreso, la que ahora debe, para Jonas, encargarse de su dirección y su limitación. Algunos pasos se han dado en los últimos años para ello.

$60 \quad$ Ibid., p. 14.

61 Jonas, H., Más cerca del perverso fin..., p. 127.

62 Afirma Jonas en el Principio de responsabilidad: "Y está en la esencia de nuestra naturaleza moral el que esa llamada que la inteligencia trasmite encuentre una respuesta en nuestro sentimiento. Es el sentimiento de la responsabilidad». Porque, «como cualquier teoría, también una teoría de la responsabilidad ha de tener en cuenta ambas cosas: el fundamento racional de la obligación - esto es, el principio legitimador subyacente de la exigencia de un «deber» vinculante- y el fundamento psicológico de su capacidad de mover la voluntad, es decir, de convertirse para el sujeto en la causa de dejar determinar su acción por aquel. Esto significa que la ética tiene un lado objetivo y un lado subjetivo: el primero tiene que ver con la razón, el segundo, con el sentimiento». Jonas, H., El principio de responsabilidad, Herder, Barcelona 2008, p. 153.

${ }^{63}$ Ibid. p. 128. 


\section{ConcLusión}

Por tanto, si nos preguntamos acerca del hombre nos encontramos a este en lo alto de la escala de seres naturales. Así, Plessner y Jonas recaen en una visión de la naturaleza que si bien reconocen antropocéntrica ${ }^{64}$, entiende al hombre no como un dominador de la naturaleza, no observandola con soberbia y presunción, sino como mayor exponente de la realización de ésta (abierto a la trascendencia) y, por ende, velador de ella ante los peligros.

Como hemos visto, Jonas y Plessner tratan de dar cuenta del hombre en la inmensidad de este cosmos que nos rodea y del que, a su vez, somos parte, tarea en la que se han empeñado multitud de filósofos y científicos a lo largo de la historia del pensamiento. Las ideas aquí expuestas a modo de iluminaciones buscan apoyar, sostener, servir como base a la idea hoy extendida del hombre integrado en la naturaleza, responsable de y ante ella.

\section{BiBLIOGRAFÍA}

Blanco, C. (2013).«Vida, interioridad y lucha. Una definición de la vida en diálogo con H. Plessner y H. Jonas» en: Ideas y valores, vol. lxii, no 151, pp. 129-141.

Cassirer, E. (1975). Antropología filosófica. Introducción a una filosofía de la cultura. México: FCE.

Duarte, M. B. (2016). «Aberturas para o mundo: da sensibilidade vegetativa ao fenômeno mental humano no pensamiento de Hans Jonas», en: Pensando - Revista de Filosofia, Vol. 7, $\mathrm{N}^{\circ} 14$.

Duch, L. (2007). «Introducción a la edición española» en: Plessner, H., La risa y el llanto. Madrid: Editorial Trotta.

González, A. (1971). «La posicionalidad excéntrica del hombre» en: Anuario Filosófico, 4, pp. 117-181.

Greene, M. (1966). «El concepto de posicionalidad. Introducción a la filosofía de Helmuth Plessner» en: Convivium, (22), pp. 39-61.

Jonas, H. (1999). El principio vida: hacia una biología filosófica. Madrid: Trotta.

- (2001). Más cerca del perverso fin y otros diálogos y ensayos. Madrid: Los libros de la catarata.

- (2005). Memorias. Barcelona: Losada.

- (2012). Pensar sobre Dios y otros ensayos. Barcelona: Herder.

Menegazzi, T. (2010). «Helmuth Plessner: antropología y bio-filosofía a comienzos del siglo XX» en: Thémata. Revista de Filosofía, no 43, pp. 289-315.

Michelini, F. (2011). Il vivente e la mancanza. Milán: Mimesis.

Plessner, H. (2007). La risa y el llanto. Madrid: Trotta.

64 Jonas «confiesa» cometer el «delito del antropomorfismo» en un sentido en el que el ser humano se vuelve medida de todas las cosas no por su razón sino por su integridad psicofísica que «representa el estado más extremo de la concreta totalidad ontológica que conocemos» (Jonas, H., Pensar sobre Dios y otros ensayos, Herder, Barcelona 2012, p. 22). 
- (2006). I gradi dell' organico e l'uomo. Introduzione all' antropologia filosofica. Turín: Bollati Boringhieri editore.

Universidad Pontificia Comillas

Juan Jesús Gutierro Carrasco jjesusguca@hotmail.com

[Artículo aprobado para publicación en enero de 2018] 